\title{
COMPOSIÇÃO DO BANCO DE SEMENTES DE UMA FLORESTA SEMIDECIDUAL SECUNDÁRIA CONSIDERANDO O SEU POTENCIAL DE USO PARA RECUPERAÇÃO AMBIENTAL ${ }^{1}$
}

\author{
Antonio Jorge Tourinho Braga ${ }^{2}$, James Jackson Griffith ${ }^{3}$, Haroldo Nogueira de Paiva ${ }^{3}$ e João Augusto \\ Alves Meira Neto ${ }^{4}$
}

\begin{abstract}
RESUMO - Este estudo teve como objetivo caracterizar o banco de sementes de um fragmento florestal na região de Viçosa, MG, bem como inferir se esse indicador pode garantir a sustentabilidade caso seja utilizado para recuperação de áreas degradadas e, ainda, comparar sua composição florística com aquelas descritas em outros estudos com bancos de sementes. Para isso, foram coletadas 20 amostras do banco de sementes em pontos escolhidos ao acaso, sendo cada amostra composta de quatro subamostras. Para a instalação do experimento no viveiro, foram utilizadas 20 caixas de madeira no formato de 50 × 50 x $15 \mathrm{~cm}$. Após 90 dias, encontraramse 508 indivíduos, dos quais foram identificadas 38 espécies, pertencentes a 34 gêneros e distribuídas em 22 famílias. O índice de diversidade (H’) foi de 2,11; já a equiabilidade (J) de 0,67 foi considerada alta quando comparada com as de outros bancos de sementes. Cecropia hololeuca $(28,91 \%)$ e Solanum erianthum $(18,67 \%)$ foram as espécies mais importantes e que podem atuar diretamente na dinâmica do processo de regeneração da mata. Verificou-se, portanto, que o banco de sementes estudado pode atuar na recomposição da vegetação de uma área degradada em condições semelhantes ao fragmento estudado, agilizando e garantindo a dinâmica do processo sucessional.
\end{abstract}

Palavras-chave: Banco de sementes, serapilheira e recuperação ambiental.

\section{COMPOSITION OF A SECONDARY FOREST SEED BANK CONSIDERING ITS POTENTIAL USE FOR ENVIRONMENTAL RECLAMATION}

\begin{abstract}
Considering its potential use in degraded environments, this study characterized the composition of a seed bank obtained from an area of typical secondary succession on the Federal University of Viçosa campus. Inferences were made whether this indicator reflects future sustainability, given the seed bank's potential for revegetating degraded sites. It floristic composition was compared with indices obtained in other similar seed bank studies. The specific site is located at the Mata da Garagem woods, a 40-year old forest fragment covering a low ridge parallel to a campus roadway. Twenty seed bank samples were collected from randomly selected points, each sample consisting of four subsamples. The experiment was installed on the campus nursery using 20 wooden boxes $(50 \times 50 \times 15 \mathrm{~cm})$. After 90 days, 508 individual plants were counted, and 38 species were identified, as belonging to 34 genera distributed among 22 families. The diversity index ( $H^{\prime}$ ) is 2.11; whereas the equability $(J)$ value of 0.67 is considered high compared to other seed bank studies. Cecropia hololeuca (28.9\%) and Solanum erianthum (18,7\%) are indicated as the most important species within the forest regeneration process. Results suggest that the seed bank studied indeed has the potential for promoting and guaranteeing an ecological succession process dynamics on degraded lands of similar ecosystems.
\end{abstract}

Keywords: Seed bank, forest litter and environmental recovery.

\footnotetext{
${ }^{1}$ Recebido em 10.06.2007 e aceito para publicação em 22.08.2008.

${ }^{2}$ Programa de Pós-Graduação em Ciência Florestal da Universidade Federal de Viçosa (UFV). E-mail: <tourinhobraga@yahoo.com.br>.

${ }_{3}^{3}$ Departamento de Engenharia Florestal da UFV. E-mail: <griffith@ufv.br>.

${ }^{4}$ Departamento de Biologia Vegetal da UFV. E-mail: <j.meira@ufv.br>.
} 


\section{INTRODUÇÃO}

O banco de sementes é composto pelas sementes viáveis, em estado de dormência primária ou secundária, presentes na superfície ou no interior do solo (HARPER, 1977). O conhecimento do seu tamanho, de sua composição e do padrão de distribuição das sementes no solo, assim como de sua dinâmica, são fatores importantes na compreensão dos mecanismos que controlam a sucessão vegetal nos trópicos (LEAL FILHO, 1992).

A composição florística e a distribuição dos propágulos que compõem o banco de sementes são afetadas tanto pelos tipos de dispersão das espécies presentes na área quanto por aqueles adotados pelas espécies das áreas adjacentes (JOLY, 1986). A contribuição de diferentes fontes de propágulos determina a estrutura da comunidade florestal, sendo essencial proteger os remanescentes de florestas para manter essas fontes (ESPÍNDOLA et al., 2003).

Todas as sementes viáveis presentes no solo constituem o banco de sementes, e o período em que a semente permanece viável no solo depende de seus atributos fisiológicos (tipo de dormência), de interações bióticas (existência de parasitas e, ou, predadores) e de condições abióticas (disponibilidade de água, luz e oxigênio). Em florestas tropicais, o banco de sementes está envolvido em pelo menos quatro processos em níveis de população e de comunidade: (i) estabelecimento de populações, (ii) manutenção da diversidade de espécies, (iii) estabelecimento de grupos ecológicos e (iv) restauração da riqueza de espécies durante a regeneração da floresta após distúrbios naturais ou antrópicos (GARDWOOD, 1989).

O banco de sementes do solo reflete a composição potencial da floresta após perturbações (BAIDER et al., 2001). A recolonização da vegetação em um ambiente perturbado ocorre, principalmente, através do banco de sementes, que vai cooperar para o equilíbrio dinâmico da área (SCHMITZ, 1992). Portanto, quanto mais aprofundadas forem as informações a respeito do banco de sementes, maiores serão as contribuições para programas de manejo, conservação e recuperação.

Diante do exposto, este estudo teve como objetivos caracterizar o banco de sementes de um fragmento florestal na região de Viçosa, MG, bem como inferir se esse indicador pode garantir a sustentabilidade caso seja utilizado para a recuperação de áreas degradadas e, ainda, comparar sua composição florística com aquelas descritas em outros estudos com bancos de sementes.

\section{MATERIAL E MÉTODOS}

\section{1. Área de Estudo}

O estudo foi realizado na "Mata da Garagem", no Campus da Universidade Federal de Viçosa (UFV), com cerca de 50 ha, no Município de Viçosa, Minas Gerais, localizado a $42^{\circ} 53^{\prime} \mathrm{W}$ e $20^{\circ} 45^{\prime} \mathrm{S}$ e aproximadamente $650 \mathrm{~m}$ de altitude. $\mathrm{O}$ fragmento florestal dessa área tem, aproximadamente, 40 anos de regeneração natural, após corte raso da cobertura original para plantio de café, sendo caracterizado por Silva et al. (1999) como Floresta Estacional Semidecidual.

Segundo o sistema de classificação de Köppen, o clima é do tipo Cwb, mesotérmico, com verões chuvosos e invernos frios e secos. A precipitação média nos últimos 30 anos foi de cerca de $1.221 \mathrm{~mm}$. No período de novembro a abril, há excedente hídrico, enquanto de abril até setembro a precipitação fica abaixo da evapotranspiração potencial, o que causa déficit hídrico nesse período. Já nos meses de setembro a novembro a precipitação volta a ser maior que a evapotranspiração, o que define uma estação seca e outra chuvosa na região de Viçosa, MG (MARANGON et al., 2003).

A serapilheira e o solo foram coletados em locais representativos do estágio médio de sucessão secundária da mata, no início do mês de março de 2005, período que corresponde ao final da estação chuvosa na região, em pontos distribuídos ao acaso, totalizando 20 amostras coletadas, cada uma composta de quatro subamostras. Para isso, foram utilizados gabaritos quadrados de madeira de $0,25 \times 0,25 \mathrm{~m}\left(0,0625 \mathrm{~m}^{2}\right)$, colocados sobre a superfície do solo, retirando-se primeiro a serapilheira e, em seguida, o solo sob esta até uma profundidade de $5 \mathrm{~cm}$, utilizando-se pá de lixo. O material coletado foi colocado em sacos plásticos de $30 \mathrm{~L}$ e transportado para o Viveiro de Pesquisas do Departamento de Engenharia Florestal (UFV-MG), onde ocorreu a instalação do experimento.

Para a montagem do experimento, foram utilizadas 20 caixas de madeira no formato de $50 \times 50 \times 15 \mathrm{~cm}$, totalizando uma área de $5 \mathrm{~m}^{2}$, as quais receberam uma camada de $3 \mathrm{~cm}$ de substrato, sendo em seguida preenchidas com o solo coletado e recobertas com 
a serapilheira. O substrato utilizado foi tratado com brometo de metila por $72 \mathrm{~h}$ e colocado para ventilar por $48 \mathrm{~h}$. Metade das amostras $(\mathrm{n}=10)$ foi distribuída em bancadas dentro da casa de vegetação sob $60 \%$ de sombreamento, sendo a outra metade distribuída em bancadas sem sombreamento. Isso simulou as condições de aplicação da técnica em condições de campo, com a possibilidade de invasão por propágulos. As irrigações não seguiram um padrão, sendo realizadas conforme as condições climáticas do dia, com o intuito de evitar o estresse do déficit hídrico.

\subsection{Avaliação do Banco de Sementes}

Foram identificados e quantificados os indivíduos que emergiram do banco de sementes ao final de 90 dias. A identificação das espécies foi feita por meio de consultas bibliográficas em literatura específica, por meio de comparação com exsicatas depositadas em herbário e também com o auxílio de pesquisadores especialistas. As espécies foram apresentadas de acordo com a classificação de Cronquist (1981), à exceção das famílias Caesalpiniaceae, Fabaceae e Mimosaceae, que foram tratadas como subfamília de Leguminosae. As espécies foram classificadas em arbóreas e herbáceas, sendo consideradas herbáceos os cipós, as ervas e as gramíneas. Além disso, para as comparações com outros estudos foram incluídos os arbustos nessa última categoria. As espécies arbóreas amostradas foram classificadas nas seguintes categorias sucessionais: pioneira, secundária inicial e secundária tardia, considerando-se o proposto por Gandolfi et al. (1995), juntamente com revisões bibliográficas.

Para as espécies arbóreas, foram tomadas as medidas de altura total $(\mathrm{H})$ e diâmetro do coleto (D), utilizandose, respectivamente, uma régua graduada em centímetro e um paquímetro digital com precisão de $0,01 \mathrm{~mm}$. A partir desses dados, estimaram-se o índice de diversidade de Shannon (H'), a equiabilidade (PIELOU, 1975), o índice de dispersão de McGuines (IGA) (BARROS e MACHADO, 1984) e os parâmetros de densidade, dominância e freqüência relativas, para a composição dos valores de importância e de cobertura (MUELLERDOMBOIS e ELLENBERG, 1974), utilizando o programa Mata Nativa 1.04 (CIENTEC, 2002).

\subsection{Análise de Agrupamento}

A similaridade entre este estudo e os dos bancos de sementes foi calculada pelo Índice de Similaridade de Sorensen (ISS). As matrizes de dados foram obtidas e analisadas pelo algoritmo de ligação completa, sendo as análises realizadas por meio do programa FITOPAC I (SHEPHERD, 1996), o que permitiu expressar os resultados na forma de dendrograma.

A composição do banco de sementes foi comparada com os resultados do levantamento florístico realizado no fragmento estudado (SOUZA, 2003) e com a composição dos seguintes estudos de bancos de sementes realizados em florestas secundárias na região e em outras localidades: da mesma "Mata da Garagem" (SOUZA et al., 2006); da "Mata da Praça dos Esportes", no Campus da UFV (FRANCO, 2005); da "Mata do Paraíso”, na região de Viçosa, MG (LEAL FILHO, 1992); e de três matas secundárias da Samarco Mineração S.A., na região de Mariana, MG (OZÓRIO, 2000).

\section{RESULTADOS E DISCUSSÃO}

\subsection{Composição do Banco de Sementes}

Um total de 508 indivíduos germinou do banco de sementes $\left(101,6 \mathrm{ind} / \mathrm{m}^{2}\right)$, sendo 291 exemplares arbóreos de 20 espécies, 17 gêneros e 13 famílias. Um indivíduo foi identificado apenas em nível de família, e dois permaneceram indeterminados. Foram encontrados 217 indivíduos herbáceos de 18 espécies e 12 famílias, sendo um indivíduo identificado em nível de família, enquanto três permaneceram indeterminados. No total, foram reconhecidas 38 espécies, distribuídas em 34 gêneros e 22 famílias (Tabela 1). Dos 508 indivíduos germinados, 267 germinaram no ambiente sombreado e 241 no ambiente sem sombreamento, o que demonstra, por meio de análise de variância (teste F), não haver diferença entre os ambientes testados no viveiro quanto ao número de indivíduos originados do banco de sementes.

Cecropia hololeuca, conhecida na região como embaúba-branca, destacou-se em número de indivíduos $(n=127)$, ou seja, $43,64 \%$ do total de indivíduos originados do banco de sementes (Tabela 1). Isso indica que as sementes dessa espécie dominam o banco de sementes do fragmento florestal em estudo e demonstra a boa viabilidade dos diásporos. As plântulas de $C$. hololeuca foram diferenciadas da Cecropia glaziovi pela coloração avermelhada da nervura principal das folhas da espécie C. glaziovi, marcante na intersecção do limbo com o pecíolo, pela coloração púrpura presente na base do limbo das folhas jovens e, ainda, pelo maior tempo de permanência das estípulas encontradas na base das folhas dessa espécie em relação a $C$. hololeuca.

R. Árvore, Viçosa-MG, v.32, n.6, p.1089-1098, 2008 
Tabela 1 - Relação das espécies arbóreas e herbáceas originadas do banco de sementes da Mata da Garagem, em Viçosa, MG, com o respectivo grupo ecológico (GE), ciclo de vida (CV) e número de indivíduos encontrados.

Table 1 - List of the tree and herbaceous species originated from "Mata da Garagem" seed bank in Viçosa/MG, with the respective ecology group $(E G)$, life cycle $(L C)$ and number of the individuals found

\begin{tabular}{|c|c|c|c|c|c|}
\hline Família & Nome Científico & Nome Regional & GE & $\mathrm{CV}$ & $\mathrm{N}^{\circ}$ Ind. \\
\hline Amaranthaceae & Alternanthera tenella Colla & Apaga-fogo & $\mathrm{H}$ & A & 1 \\
\hline \multirow[t]{2}{*}{ Annonaceae } & Annona cacans Warm. & Araticum & SI & $\mathrm{P}$ & 3 \\
\hline & Indeterminada & & $\mathrm{NC}$ & $\mathrm{P}$ & 1 \\
\hline \multirow[t]{8}{*}{ Asteraceae } & Ageratum conyzoides $\mathrm{L}$. & Mentrasto & $\mathrm{H}$ & A & 3 \\
\hline & Baccharis sp. & & & $\mathrm{P}$ & 2 \\
\hline & Conyza canadensis (L.) Cronquist & Buva & $\mathrm{H}$ & A & 4 \\
\hline & Erechtites hieraciifolius (L.) Raf. ex DC. & Capiçoba & $\mathrm{H}$ & A & 2 \\
\hline & Eupatorium laevigatum Lam. & Formigueira & $\mathrm{H}$ & A & 2 \\
\hline & Galinsoga sp. & Fazendeiro & $\mathrm{H}$ & A & 5 \\
\hline & Sonchus oleraceus L. & Serralha & $\mathrm{H}$ & A & 2 \\
\hline & Vernonia diffusa (Less.) H. Rob. & Pau-de-fumo & PI & $\mathrm{P}$ & 3 \\
\hline Begoniaceae & Begonia cucullata Willd. & Azedinha-do-brejo & $\mathrm{H}$ & $\mathrm{P}$ & 1 \\
\hline \multirow[t]{2}{*}{ Cecropiaceae } & Cecropia hololeuca Miq. & Embaúba-branca & PI & $\mathrm{P}$ & 127 \\
\hline & Cecropia glaziovi Warm. & Embaúba & PI & $\mathrm{P}$ & 14 \\
\hline Erytroxylaceae & Erythroxylum pelleterianum A. St-Hil & Sessenta-e-um & PI & $\mathrm{P}$ & 1 \\
\hline \multirow[t]{2}{*}{ Euphorbiaceae } & Alchornea glandulosa Poepp. & Casca-doce & PI & $P$ & 1 \\
\hline & Croton urucurana Baill. & Sangra-d'agua & PI & $\mathrm{P}$ & 1 \\
\hline \multirow[t]{2}{*}{ Flacourtiaceae } & Banara kuhlmannii (Sleumer) Sleumer & & $\mathrm{NC}$ & $\mathrm{P}$ & 1 \\
\hline & Casearia sp. & & SI & $\mathrm{P}$ & 8 \\
\hline Labiatae & Hyptis sp. & & $\mathrm{H}$ & $\mathrm{NC}$ & 12 \\
\hline Leguminosae & Apuleia leiocarpa (Voge1.) J. F. Macbr. & Garapa & SI & $\mathrm{P}$ & 3 \\
\hline \multicolumn{6}{|l|}{ Caesalpinioideae } \\
\hline Malvaceae & Sida sp. & Vassourinha & $\mathrm{H}$ & $\mathrm{P}$ & 19 \\
\hline \multirow[t]{3}{*}{ Melastomataceae } & Leandra purpurascens (DC.) Cong. & Pixirica & $\mathrm{H}$ & $\mathrm{P}$ & 11 \\
\hline & Miconia sp. & & PI & $\mathrm{P}$ & 28 \\
\hline & Miconia cinnamomifolia (DC.) Naudin & Quaresminha & PI & $\mathrm{P}$ & 26 \\
\hline Moniniaceae & Siparuna guianensis Aubl & Folha-santa & $\mathrm{SC}$ & $P$ & 16 \\
\hline Oxiladaceae & Oxalis corniculata $\mathrm{L}$. & Trevo & $\mathrm{H}$ & $P$ & 8 \\
\hline Rubiaceae & Psychotria sessilis (Vell.) Müll. Arg. & Cafezinho-do-mato & $\mathrm{ST}$ & $\mathrm{P}$ & 2 \\
\hline Piperaceae & Pothomorphe umbellata(L.) Miq. & Capeva & $\mathrm{H}$ & $\mathrm{P}$ & 9 \\
\hline Poaceae & Indeterminada & & $\mathrm{H}$ & $\mathrm{P}$ & 106 \\
\hline Sapindaceae & Serjania erecta Radlk. & Falso-guaraná & $\mathrm{H}$ & $\mathrm{P}$ & 7 \\
\hline \multirow[t]{5}{*}{ Solanaceae } & Physalis angulata $\mathrm{L}$. & Camuru & $\mathrm{H}$ & A & 1 \\
\hline & Solanum americanum Mill. & Maria-pretinha & $\mathrm{H}$ & A & 17 \\
\hline & Solanum erianthum D. Don & Fruta-de-pomba & PI & $\mathrm{P}$ & 19 \\
\hline & Solanum sp. & & PI & $P$ & 11 \\
\hline & Vassobia breviflora (Sendtn.) Hunz. & Marianeira & PI & $\mathrm{P}$ & 10 \\
\hline Tiliaceae & Luehea grandiflora Mart. & Açoita-cavalo & SI & $P$ & 2 \\
\hline Trigoniaceae & Trigonia sp. & Cipó & $\mathrm{H}$ & $\mathrm{P}$ & 1 \\
\hline Ulmaceae & Trema micrantha (L.) Blume & Trema & PI & $P$ & 11 \\
\hline Verbenaceae & Aegiphila sellowiana A. St-Hil & Papagaio & PI & $\mathrm{P}$ & 1 \\
\hline \multicolumn{2}{|c|}{ Indeterminadas Abóreas } & & & & 2 \\
\hline \multicolumn{2}{|c|}{ Indeterminadas Herbáceas } & & & & 4 \\
\hline \multicolumn{2}{|l|}{ Total } & & & & 508 \\
\hline
\end{tabular}

SI = Secundária Inicial $;$ ST = Secundária Tardia $; \mathrm{H}=$ herbácea; $\mathrm{NC}=$ Não Classificação; $\mathrm{PI}=$ Pioneira; $\mathrm{CV}=\mathrm{Ciclo}$ de Vida; $\mathrm{A}=\mathrm{Anual}$; e $\mathrm{P}=$ Perene. $S I=$ Initial Secondary; $S T=$ Late Secondary; $H=$ Herbaceous; $N C=$ Not Classified $; P I=$ Pioneer $; C V=L i f e C y c l e$; $A=$ Annual $; P=$ Perennial .

R. Árvore, Viçosa-MG, v.32, n.6, p.1089-1098, 2008 
Das espécies arbóreas, a família Solanaceae apresentou três espécies, representando $14 \%$ do total de indivíduos $(\mathrm{n}=58)$, enquanto Anonnaceae, Cecropiaceae, Euphorbiaceae, Flacortiaceae e Melastomataceae contribuíram com duas espécies cada. Cecropiaceae obteve o maior número de indivíduos ( $\mathrm{n}=141$ ), correspondendo a $48 \%$ do total amostrado. O número de indivíduos da família Cecropiaceae foi maior que o encontrado no estudo do banco de sementes de um fragmento de mata da região de Viçosa, MG, com 74 indivíduos (SILVAJÚNIOR et al., 2001). A mesma situação também foi observada por Souza (2003) na "Mata da Garagem", em comparação com as cinco épocas distintas de coleta isoladamente: outubro com 39 indivíduos e dezembro de 2001 com 48 indivíduos; e fevereiro, 56 indivíduos, abril com 102 indivíduos e junho de 2002 com 82 indivíduos da espécie. Ressaltase que em ambos os trabalhos a amostragem empregada foi a mesma utilizada neste estudo.

A família Asteraceae contribuiu com sete espécies herbáceas, concentrando $9 \%$ do total de indivíduos herbáceos, acompanhada da família Solanaceae, com duas espécies, o que significa $8 \%$ do número total desses indivíduos, enquanto Poaceae apresentou o maior número de indivíduos herbáceos $(\mathrm{n}=106)$, o que representa $48,8 \%$ do total quantificado. O total de indivíduos herbáceos foi menor que o de indivíduos arbóreos, diferindo de outros trabalhos realizados com banco de sementes em florestas secundárias da região e outras localidades (LEAL FILHO, 1992; OZÓRIO, 2000; FRANCO, 2005; SOUZA, 2006). A maior riqueza de espécies arbóreas pode ser explicada pelo reduzido número de sementes de espécies herbáceas no banco de sementes, em decorrência do estágio médio de sucessão secundária da floresta, o que reduz a presença desse grupo no local. De acordo com Baider et al. (2001), com o amadurecimento da floresta ocorre redução na densidade de sementes viáveis e na de sementes herbáceas, bem como, finalmente, aumento na densidade de sementes arbustivas e arbóreas.

O índice de diversidade de Shannon ( $\left.\mathrm{H}^{\prime}\right)$, que foi estimado exclusivamente para as espécies arbóreas, apresentou valor de 2,11. Esse valor representa diversidade baixa quando comparado com o da diversidade de uma floresta madura, porém semelhante em comparação com os valores relatados por Araújo et al. (2001) em bancos de sementes na Amazônia, demonstrando que o índice varia entre $\mathrm{H}^{\prime}=1,12$ e $\mathrm{H}^{\prime}=$
2,23. Já a eqüabilidade ( $\mathbf{J}$ ) foi de 0,67 , valor maior do que o mais alto encontrado $(\mathrm{J}=0,52)$ no banco de sementes do solo de florestas secundárias na Amazônia Oriental (ARAÚJO et al., 2001). Segundo Meira Neto e Martins (2000), nas Florestas Estacionais Semidecíduas, em Minas Gerais, o índice de diversidade varia entre 3,2 e 4,2 e a eqüabilidade $(\mathrm{J})$, entre 0,73 e 0,88 .

A baixa diversidade ex situ encontrada no estudo conduzido no viveiro, quando comparada com os dados daqueles autores e a observada por Souza (2003) na vegetação in situ da "Mata da Garagem", local da coleta, pode ser explicada pelo valor de eqüabilidade encontrado. $\mathrm{O}$ valor baixo do índice de diversidade de Shannon indica a homogeneidade do banco de sementes estudado, o que significa que poucas espécies do local de coleta são responsáveis pela maior proporção de sementes no solo.

As espécies secundárias corresponderam a uma dominância relativa de $4,9 \%$, valores baixos se comparados com os 95,1\% referentes às espécies pioneiras. Tais valores comprovam que a composição do banco de sementes da mata em questão é dominada por sementes do grupo ecológico das pioneiras. Segundo Scherer e Jarenkow (2006), a presença de espécies dependentes de luz, juntamente aquelas tolerantes à sombra no banco de sementes, indica alto potencial de regeneração do componente arbóreo, no caso de formação de clareira ou outras perturbações na estrutura florestal presente. Assim, a presença de Solanum. erianthum, bem como de Alchornea glandulosa e de Croton_urucurana, espécies pioneiras que também se destacaram na composição florística do banco de sementes, pode assegurar a rápida cobertura e proteção do solo exposto, acelerando o processo de sucessão ecológica de uma área degradada.

Três espécies, S. erianthum, $C$. hololeuca e Trema micrantha, apresentaram os maiores valores de dominância relativa (DoR), representando, juntas, 78\% do valor total (Tabela 2). Os valores estimados se devem ao porte alcançado pelos indivíduos de $S$. erianthum e $T$. micrantha e à proporção de cobertura no caso da espécie $C$. hololeuca.

A espécie pioneira $S$. erianthum, muito freqüente nos estágios iniciais da sucessão secundária na região, apresentou dominância relativa de $40,2 \%$, e o seu desenvolvimento superou as demais espécies, com uma média de altura dos indivíduos de $11,8 \mathrm{~cm}$, alguns

R. Árvore, Viçosa-MG, v.32, n.6, p.1089-1098, 2008 
chegando a atingir $25 \mathrm{~cm}$ de altura e 7,95 $\mathrm{mm}$ de diâmetro aos 90 dias. De acordo com Martínez-Ramos e SotoCastro (1993), em ecossistemas florestais os propágulos que alcançam o solo são oriundos, predominantemente, de espécies presentes no local. Já outros propágulos de espécies localizadas em áreas vizinhas ou, mesmo, mais distantes, como é o caso dessa espécie, são depositados no banco de sementes, dada a eficiência de seus mecanismos de dispersão. Essa contribuição mantém a estrutura e dinâmica do fragmento florestal.

A espécie que apresentou maior abundância, expressa em densidade relativa (DR), foi C. hololeuca, com 43,6\%, seguida de Miconia sp. (9,6\%), Miconia cinnamomifolia $(8,9 \%)$ e $S$. erianthum $(6,5 \%)$, mostrando que o banco de sementes estudado é composto por grande quantidade de sementes viáveis dessas espécies. Essas mesmas quatro espécies ainda acumularam, juntas, uma dominância relativa de $68,7 \%$ na avaliação de todos os indivíduos do banco de sementes. Nos trabalhos de Souza (2003) e Franco (2005), C. hololeuca foi também a espécie com maior densidade nos bancos de sementes por eles estudados. Conforme o segundo autor, a presença marcante desse gênero em bancos de sementes de florestas tropicais é extremamente importante para a regeneração desses tipos de florestas após distúrbios. Suas sementes são dotadas de grande longevidade, podendo ficar estocadas por vários anos no solo (HOLTHUIJZEN e BOERBOOM, 1982). O grande número de indivíduos originados do banco de sementes destacou essa espécie como a mais importante para a regeneração natural, após a abertura de clareiras nas florestas da região de Viçosa, MG, indicando, ainda, o potencial de uso dessa espécie no reflorestamento planejado de áreas degradadas.

Tabela 2 - Espécies amostradas do banco de sementes da Mata da Garagem, Viçosa, MG, listadas em ordem decrescente pelo Valor de Importância (VI).

Table 2 - Species sampled from the "Mata da Garagem" Forest seed bank in Viçosa, Minas Gerais, listed by decreasing Importance Value (IV)

\begin{tabular}{|c|c|c|c|c|c|c|c|}
\hline Nome Científico & $\mathrm{N}$ & H Med. & DR & FR & DoR & $\mathrm{VC} \%$ & VI $\%$ \\
\hline Cecropia hololeuca & 127 & 3,85 & 43,64 & 17,59 & 25,50 & 34,57 & 28,91 \\
\hline Solanum erianthum & 19 & 11,84 & 6,53 & 9,26 & 40,22 & 23,37 & 18,67 \\
\hline Trema micrantha & 11 & 6,17 & 3,78 & 7,41 & 12,31 & 8,05 & 7,83 \\
\hline Miconia sp. & 28 & 2,00 & 9,62 & 8,33 & 1,25 & 5,44 & 6,40 \\
\hline Miconia cinnamomifolia & 26 & 2,13 & 8,93 & 7,41 & 1,31 & 5,12 & 5,88 \\
\hline Siparuna guianensis & 16 & 2,14 & 5,50 & 9,26 & 1,90 & 3,70 & 5,55 \\
\hline Solanum sp. & 11 & 5,45 & 3,78 & 6,48 & 5,03 & 4,41 & 5,10 \\
\hline Cecropia glaziovi & 14 & 3,43 & 4,81 & 5,56 & 3,32 & 4,06 & 4,56 \\
\hline Vassobia breviflora & 10 & 2,65 & 3,44 & 5,56 & 3,28 & 3,36 & 4,09 \\
\hline Casearia sp. & 8 & 1,75 & 2,75 & 5,56 & 0,42 & 1,58 & 2,91 \\
\hline Annona cacans & 3 & 6,67 & 1,03 & 2,78 & 1,00 & 1,02 & 1,60 \\
\hline Apuleia leiocarpa & 3 & 6,67 & 1,03 & 2,78 & 0,60 & 0,82 & 1,47 \\
\hline Vernonia diffusa & 3 & 1,33 & 1,03 & 1,85 & 0,30 & 0,67 & 1,06 \\
\hline Luehea grandiflora & 2 & 2,75 & 0,69 & 1,85 & 0,29 & 0,49 & 0,94 \\
\hline Alchornea glandulosa & 1 & 17,50 & 0,34 & 0,93 & 1,40 & 0,87 & 0,89 \\
\hline Croton urucurana & 1 & 12,00 & 0,34 & 0,93 & 0,70 & 0,52 & 0,66 \\
\hline Psychotria sessilis & 2 & 1,75 & 0,69 & 0,93 & 0,27 & 0,48 & 0,63 \\
\hline Aegiphila sellowiana & 1 & 5,50 & 0,34 & 0,93 & 0,28 & 0,31 & 0,51 \\
\hline Banara kuhlmannii & 1 & 7,00 & 0,34 & 0,93 & 0,26 & 0,30 & 0,51 \\
\hline Erythroxylum pelleterianum & 1 & 5,00 & 0,34 & 0,93 & 0,17 & 0,26 & 0,48 \\
\hline NI1 & 1 & 4,00 & 0,34 & 0,93 & 0,08 & 0,21 & 0,45 \\
\hline NI2 & 1 & 2,00 & 0,34 & 0,93 & 0,07 & 0,21 & 0,45 \\
\hline $\mathrm{NI}$ & 1 & 1,50 & 0,34 & 0,93 & 0,04 & 0,19 & 0,44 \\
\hline Total & 291 & 4,07 & 100 & 100 & 100 & 100 & 100 \\
\hline
\end{tabular}

Sendo N = Número de Indivíduos; H Med. = Altura Média $(\mathrm{cm}) ; \mathrm{DR}=$ Densidade Relativa; FR = Freqüência Relativa; DoR = Dominância

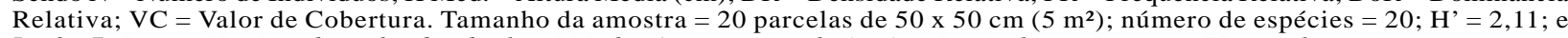
$\mathrm{J}=0,67$. Being: $N=$ Number of Individuals; H Med =Average Height $(\mathrm{cm}) ; D R=$ Relative Density; FR = Relative Frequency; DoR $=$ Relative Dominance $; V C=$ Relative Cover. Sample size $=20$ plots, $50 \times 50 \mathrm{~cm}\left(5 \mathrm{~m}^{2}\right)$ each; number of species $=20 ; H^{\prime}=2.11$ and $\bar{J}=0.67$.

R. Árvore, Viçosa-MG, v.32, n.6, p.1089-1098, 2008 
Considerando a densidade absoluta por categoria sucessional, as espécies secundárias, juntas, apresentaram uma média de $3,6 \mathrm{ind} / \mathrm{m}^{2}$, correspondendo a uma densidade absoluta de $36.000 \mathrm{ind} / \mathrm{ha}$, enquanto as espécies pioneiras tiveram uma média bem superior (50,6 ind $\left./ \mathrm{m}^{2}\right)$, o que corresponde a uma densidade absoluta de $506.000 \mathrm{ind} / \mathrm{ha}$. Tais dados reforçam, mais uma vez, a predominância dos indivíduos das espécies pioneiras no banco de sementes em estudo, demonstrando a alta representatividade destes tipos de espécies. Esse resultado é importante porque comprova o grande potencial do banco de sementes como fornecedor de espécies aptas para iniciar o processo de sucessão de uma área degradada em condições ecológicas semelhantes à deste estudo.

Os indivíduos de seis espécies ( $C$. hololeuca, S.erianthum, Siparuna guianenses, Miconia sp, $T$. micrantha e M. cinnamomifolia) apresentaram freqüência relativa de 59,2\%. Analisando o valor de importância (VI), observou-se o predomínio de $C$. hololeuca $(28,9 \%)$, que se destacou pelo elevado número de indivíduos, e de S. erianthum $(18,7 \%)$, que está em função do porte dos indivíduos amostrados. Essas duas espécies ocuparam as primeiras posições em valor de cobertura (VC), obtendo, juntas, 57,9\% da estimativa total (Tabela 2).

Para que a transposição tenha sucesso, algumas ações são fundamentais. Conforme recomendou Braga (2005), entre outras medidas, é necessário atentar para a irrigação até o início da estação chuvosa, principalmente nos primeiros 15 dias, considerados o período crítico. Também, deve-se observar o ataque de pragas como a formiga cortadeira e o grilo, de modo a oferecer suporte ao desenvolvimento dos propágulos, bem como evitar a perda da viabilidade desse material biológico.

Fundamentado nos resultados, pode-se afirmar que, apesar da baixa diversidade florística encontrada, o banco de sementes pesquisado é formado por espécies representativas da fase inicial da dinâmica sucessional. Esse resultado indica que essa fonte pode contribuir, de forma positiva, para a utilização da técnica de revegetação, com o propósito de estabelecer a cobertura vegetal de uma área degradada, mesmo não contendo espécies dos estágios mais avançados de sucessão na sua composição. A ausência de espécies tardias pode ser compensada por intervenções complementares, como o enriquecimento do banco de sementes com propágulos de espécies autóctones do bioma, dando preferência às espécies que ocorrem na região.

\subsection{Similaridade Florística e Agregação das Espécies}

A composição florística do banco de sementes deste estudo comparada com a florística encontrada por Souza et al. (2006), cujo trabalho realizado com bancos de sementes objetivou avaliar a sazonalidade da serapilheira do mesmo local da "Mata da Garagem", apresentou a maior similaridade florística entre todos os estudos comparados, conforme mostrado no dendograma da Figura 1. De acordo com Mueller-Dombois e Ellenberg (1974), podem-se considerar duas comunidades floristicamente similares quando o índice de Sorensen é igual ou superior a 0,50 , o que foi evidenciado com o valor (ISS) de 0,73 , ao comparar os dois estudos. Isso reafirma que a maioria das sementes que compõem o banco de sementes estudado é proveniente de espécies presentes na mata.

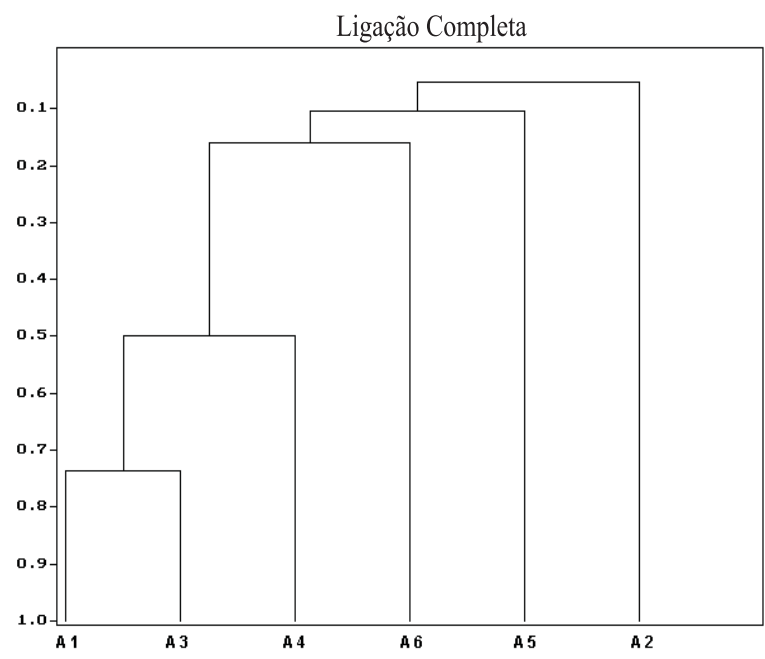

Figura 1 - Dendrograma da análise de agrupamento mostrando o nível de similaridade entre o banco de sementes deste estudo (A1) com a composição florística da Mata da Garagem, que foi o local de coleta (SOUZA, 2003) (A2) e os bancos de sementes analisados por Souza (2003) (A3), Franco (2005) (A4), Leal Filho (1992) (A5) e Ozório (2000) (A6).

Figures 1-Dendrogram grouping analysis showing the similarity level between seed banks in the present study (A1) and the floristic composition of "Mata da Garagem" Forest, where the collection was conducted (SOUZA, 2003) (A2), and the seed banks analyzed by Souza (2003) (A3), Franco (2005) (A4), Leal Filho (1992) (A5) and Ozório (2000) (A6).

R. Árvore, Viçosa-MG, v.32, n.6, p.1089-1098, 2008 
Ao comparar os resultados da florística deste trabalho com a do banco analisado por Franco (2005), também ficou comprovada a similaridade (ISS) de 0,50 na composição dos dois bancos. Tal similaridade pode ser explicada pela proximidade das duas matas, utilizadas como fonte de coleta de material.

Muito embora fosse esperada a ocorrência de espécies similares na composição florística do banco de sementes com a obtida por Leal Filho (1992), visto que os dois fragmentos de floresta se localizam na mesma região do Município de Viçosa, MG os dados da composição florística do banco de sementes deste último, bem como o de Ozório (2000), apresentaram, quando comparados com os dados desta pesquisa, índices de similaridade inferiores a 0,20. Os valores encontrados apontaram que as composições florísticas dos bancos contrastados não são similares.

Ao confrontar, entretanto, a composição do banco deste trabalho com a do banco estudado por Ozório (2000), que foi coletado de um fragmento localizado na região de Mariana, MG, houve baixa similaridade, interpretada como efeito da distância entre os dois fragmentos onde foram realizadas as coletas ( $135 \mathrm{~km}$, aproximadamente). Nesse caso, outros fatores como a altitude (que varia de 530 a $1.150 \mathrm{~m}$ entre os locais de coleta) podem favorecer a mudança gradual na composição das espécies desses fragmentos. A área pesquisada neste estudo encontravase sob o Domínio de Floresta Atlântica, Subdomínio de
Floresta Estacional Semidecidual, enquanto a área de Mariana estava entre esse domínio e o Domínio do Cerrado.

A análise indicou menor similaridade entre o banco de sementes ex situ (viveiro) com a composição florística in situ, do próprio fragmento florestal onde o material deste estudo foi coletado. Encontraram-se apenas três espécies comuns nessa comparação: Apuleia Leiocarpa, Erythroxylum pelleterianum e Luehea grandiflora, o que mostra a grande mobilidade dos diásporos dessas espécies. Tal resultado não é contraditório, pois grande parte das sementes que compuseram o banco se originou de indivíduos presentes em outros locais da mata ou, mesmo, em fragmentos próximos, como é o caso da "Mata da Praça dos Esportes" (FRANCO, 2005) e da "Mata da Silvicultura" (MEIRA-NETO e MARTINS, 2003), que compõem a metacomunidade das florestas regionais. Resultados semelhantes foram encontrados por Franco (2005), que analisou o banco de sementes e a regeneração natural em um trecho de Floresta Estacional Semidecidual no Campus da Universidade Federal de Viçosa, em Viçosa, MG Nesse trabalho, a regeneraçãonatural daárea foi comparada comobancode sementes dali coletado.Aanálise de similaridade florística indicou que os dois também não eram similares. O mecanismo de dispersão das espécies localizadas nas bordas desses fragmentos contribuiu para a formação e caracterização desses bancos de sementes e para o mecanismo de manutenção e recuperação dessas matas.

Tabela 3 - Índice de dispersão de McGuinnes (IGA) nas espécies originadas do banco de sementes da Mata da Garagem, utilizado para avaliar o grau de agregação das espécies e obtido da relação entre a densidade observada e a densidade esperada

Table 3 - McGuinnes Dispersion Index (IGA) for "Mata da Garagem" Forest seed bank species, used for evaluating species aggregation degree, obtained from the relation between observed density and expected density

\begin{tabular}{|c|c|c|}
\hline Nome Científico & IGA & Classificação IGA \\
\hline$\overline{\text { Aegiphila sellowiana }}$ & 0,97 & Uniforme \\
\hline Alchornea glandulosa & 0,97 & Uniforme \\
\hline Annona cacans & 0,92 & Uniforme \\
\hline Apuleia leiocarpa & 0,92 & Uniforme \\
\hline Banara kuhlmannii & 0,97 & Uniforme \\
\hline Casearia $\mathrm{sp}$ & 1,12 & Tendência ao Agrupamento \\
\hline Cecropia glaziovi & 1,96 & Tendência ao Agrupamento \\
\hline Cecropia hololeuca & 2,12 & Agregada \\
\hline Croton urucurana & 0,97 & Uniforme \\
\hline Erythroxylum pelleterianum & 0,97 & Uniforme \\
\hline Luehea grandiflora & 0,95 & Uniforme \\
\hline Miconia cinnamomifolia & 2,54 & Agregada \\
\hline Miconia sp & 2,34 & Agregada \\
\hline Vernonia diffusa & 1,42 & Tendência ao Agrupamento \\
\hline Psychotria sessilis & 1,95 & Tendência ao Agrupamento \\
\hline Siparuna guianensis & 1,15 & Tendência ao Agrupamento \\
\hline Solanum erianthum & 1,37 & Tendência ao Agrupamento \\
\hline Solanum sp & 1,28 & Tendência ao Agrupamento \\
\hline Trema micrantha & 1,08 & Tendência ao Agrupamento \\
\hline Vassobia breviflora & 1,40 & Tendência ao Agrupamento \\
\hline Indeterminada 1 & 0,97 & Uniforme \\
\hline Indeterminada 2 & 0,97 & Uniforme \\
\hline Indeterminada 3 & 0,97 & Uniforme \\
\hline
\end{tabular}

R. Árvore, Viçosa-MG, v.32, n.6, p.1089-1098, 2008 
Pela aplicação do índice de dispersão de McGuinnes (IGA), constatou-se que as espécies pioneiras, em sua maioria $(70 \%)$, apresentaram comportamento agregado ou com tendência ao agrupamento (Tabela 3). O padrão de distribuição agregado foi observado apenas nas espécies $C$. hololeuca, M. cinnamomifolia e Miconia sp., enquanto as espécies $C$. glaziovi, S. erianthum, T. micrantha e $S$. guianenses, que estiveram entres as 10 espécies com maior valor de importância, apresentaram tendência ao agrupamento. A mesma tendência ao agrupamento das sementes germinadas dos gêneros Cecropia e Trema também foi observado por Silva Junior et al. (2001) e por Souza (2003), no gênero Cecropia.

Para entender melhor a distribuição dessas sementes na floresta, é necessário melhor compreensão dos agentes que atuam na sua dispersão, como o vento e, principalmente, a fauna local, bem como a importância dos obstáculos naturais e do tamanho e tipo de sementes (BARROS e MACHADO, 1984).

\section{CONCLUSÃO}

A composição florística do banco de sementes estudado foi dominada por espécies arbóreas pioneiras.

Cecropia hololeuca foi a espécie mais abundante e Solanum erianthum, a que obteve maior crescimento.

O estudo do banco de sementes comprovou que este possui potencial para revegetar áreas degradadas, pois garante o início e dá o suporte necessário para o avanço da dinâmica sucessional.

A técnica de transposição do banco de sementes pode ser otimizada ao ser manejada com intervenções complementares em campo, especialmente para contemplar as espécies características de estágios mais avançados de sucessão.

\section{REFERÊNCIAS}

Á CAPES e ao CNPq pelas bolsas de estudo e pesquisa.

\section{REFERÊNCIAS}

ARAÚJO, M. M. et al. Densidade e composição florística do banco de sementes do solo de florestas sucessionais na região do Baixo Rio Guamá, Amazônia Oriental. Scientia Florestalis, n.59, p.115-130, 2001.
BAIDER, C.; TAABARELLI, M.; MANTOVANI, W. The soil seed bank during Atlantic forest regeneration in southeast Brazil. Revista Brasileira de Biologia, v.61, n.1, p.35-44, 2001.

BARROS, P. L. C.; MACHADO, S. A. Aplicação do índice de dispersão em espécies de florestas tropicais da Amazônia Brasileira. Curitiba: FUPEF, 1984. 44p. (Série Científica, 1)

BRAGA, A. J. T. Enriquecimento de serapilheira com espécies arbóreas aptas para recuperação de áreas degradadas. 2005. 81f. Dissertação (Mestrado em Ciência Florestal) - Universidade Federal de Viçosa, Viçosa, MG, 2005.

CIENTEC. Mata Nativa 1.04: Manual do Usuário. Viçosa, MG: 2002. 129p.

CRONQUIST, A. An integrated system of classification of flowering plants. New York: Columbia University, 1981. 1262p.

ESPÍNDOLA, M. B.; VIEIRA, N. K.; REIS, A. A chuva e o banco de sementes na restauração de ecossistemas. In: CONGRESSO DE ECOLOGIA DO BRASIL, 4., 2003, Fortaleza. Anais...Fortaleza: CEB, 2003. p.562-564.

FRANCO, B. K. S. Análise do banco de sementes e da regeneração natural em um trecho de floresta estacional semidecidual no campus da Universidade Federal de Viçosa, Viçosa, MG. 2005. 73f. Dissertação (Mestrado em Ciência Florestal) - Universidade Federal de Viçosa, Viçosa, MG, 2005.

GANDOLFI, S.; LEITÃO FILHO, H. F.; BEZERRA, C. L. E. Levantamento florístico e caráter sucessional das espécies arbustivo arbóreas de uma floresta mesófila semidecídua no município de Guarulhos, SP. Revista Brasileira de Biologia, v.55, n.4, p.753-767, 1995.

GARDWOOD, N. C. Tropical soil seed banks: a review. In: LECK, M.; PARKER, V.; SIMPSON, R. (Eds.). Ecology of soil seed banks. San Diego: Academic Press, 1989. p.149-209.

R. Árvore, Viçosa-MG, v.32, n.6, p.1089-1098, 2008 
HARPER, J. L. Population biology of plants. London: Academic Press, 1977. 892p.

HOLTHUiJZEN, M. A.; BOERBOOM, J. H. A. The cecropia seedbank in the Surinam lowland rain forest. Biotropica, v.14, n.1, p.62-68, 1982.

JOLY, C. A. Heterogeneidade ambiental e diversidade de estratégias adaptativas de espécies arbóreas de Mata de Galeria. In: SIMPÓSIO ANUAL DA ACADEMIA DE CIÊNCIAS DE SÃO PAULO - Perspectivas de Ecologia Teórica, 10., 1986, São Paulo. Anais...São Paulo: ACIESP, 1986. p.19-38.

LEAL FILHO, N. Caracterização do banco de sementes de três estádios de uma sucessão vegetal na Zona da Mata de Minas Gerais. 1992. 116f. Dissertação (Mestrado em Ciência Florestal) - Universidade Federal de Viçosa, Viçosa, MG, 1992.

MARANGON, L.; SOARES, J. J.; FELICIANO, A. L. P. Florística arbórea da Mata da Pedreira, município de Viçosa, Minas Gerais. Revista Árvore, v.27, n.2, p.207-215, 2003.

MARTÍNEZ-RAMOS, M.; SOTO-CASTRO, A. Seed rain and advanced regeneration in a tropical rain forest. Vegetatio, v.107/108, p.299-318, 1993.

MEIRA NETO, J. A. A.; MARTINS, F. R. Estrutura do sub-bosque herbáceo-arbustivo da mata da silvicultura, uma floresta estacional semidecidual no município de Viçosa/MG. Revista Árvore, v.27, n.4, p.459-471, 2003.

MUELLER-DOMBOIS, D.; ELLENBERG, H. A. Aims and methods of vegetation ecology. New York: John Wiley, 1974. 547p.

OZÓRIO, T. F. Potencial de uso da serapilheira na recuperação de áreas degradadas por mineração de ferro, Mariana - MG. 2000. 62f. (Mestrado em Ciência Florestal) - Universidade Federal de Viçosa, Viçosa, MG, 2000.

R. Árvore, Viçosa-MG, v.32, n.6, p.1089-1098, 2008
PIELOU, E. C. Ecological diversity. New York: Wiley, 1975. 165p.

SCHERER, C.; JARENKOW, J. A. Banco de sementes de espécies arbóreas em floresta estacional no Rio Grande do Sul, Brasil.

Revista Brasileira Botânica, v.29, n.1, p.67-77, 2006.

SCHIMTZ, M. C. Banco de sementes no solo em áreas do reservatório da UHE Paraibuna. In: KAGEYAMA, P. Y. Recomposição da vegetação com espécies arbóreas Nativas em reservatórios de usinas hidrelétricas da CESP. Série IPEF, v.8, n.25, p.7-8, 1992.

SILVA, A. F.; SANTOS, E. R.; SOARES JÚNIOR, F. J. Levantamento florístico de um trecho de floresta estacional semidecidual na Zona da Mata, Viçosa - MG. In: ERBOT - ENCONTRO DE BOTÂNICA - Conservação, manejo e recuperação de bacias hidrográficas, 21, 1999, Vitória, ES. Anais... Vitória: SSB/SECCIONAL MG/ES, 1999. p.56.

SILVA JÚNIOR, W. M.; ÓZORIO, T. F.; DE MARCO JÚNIOR, P. M. A serapilheira pode ser usada como fonte de sementes para recuperação de áreas degradadas? 2001 (Manuscrito).

SHEPHERD, G. J. Fitopac 1.0: manual do usuário. Campinas: UNICAMP, 1996.

SOUZA, P. A. Estudo da sazonalidade da serapilheira sobre o banco de sementes visando seu uso na recuperação de áreas degradadas. 2003130 f. Tese (Doutorado em Ciência Florestal) - Universidades Federais de Viçosa, Viçosa, MG, 2003.

SOUZA, P. A. et al. Avaliação do banco de sementes contido na serapilheira de um fragmento florestal visando recuperação de áreas degradadas. Cerne, v.12, n.1, p.56-67, 2006. 